\title{
Parameterization of Solar Radiation Absorption by Snow-ice Cover in the Thermodynamic Sea Ice Model of the Sea of Azov
}

\author{
D. D. Zavyalov ${ }^{\bowtie}$, T. A. Solomakha \\ Marine Hydrophysical Institute of RAS, Sevastopol, Russian Federation \\ zavyalov.dd@mhi-ras.ru
}

Purpose. The work is aimed at assessing the influence of choice of the parameterization scheme of the snow and ice radiation features upon reproduction of seasonal evolution of the snow-ice cover thickness and temperature distribution in it in the Taganrog Bay top part.

Methods and Results. Thermal seasonal dynamics of the snow-ice cover thickness in the northeastern part of the Taganrog Bay was studied using a non-stationary thermodynamic model of sea ice. The model reproduces formation of ice and accumulation of snow on its surface, spatial-temporal change in their thermophysical characteristics, melting of the snow-ice cover, vertical distribution of temperature, and solar radiation absorbed in its thickness at a preset timed data on the meteorological parameters. In the numerical solution of the heat conductivity equation for snow and ice including a radiation source, a computational grid permitting to maintain spatial resolution of the temperature profiles in the snow-ice cover during its melting and growth was applied. Two variants of parameterization of solar radiation transfer in the sea ice were considered. The first version assumed exponential decay of radiation with the constant transmittance and extinction coefficients. In the second one, a two-layer scheme of the solar radiation penetration into ice was used; it simulated the near-surface transition layer. Attenuation of intensity of solar radiation in the snow thickness was described by the Bouguer-Lambert law with the extinction coefficient both as independent of the snow thermophysical characteristics and as represented by the function of its density. The numerical experiments with the purpose to reproduce seasonal evolution of the snow-ice cover thickness and its vertical temperature profile in the Taganrog Bay top part were performed for the winter season, 2016/17. Comparative analysis of the simulation results and the sea ice thickness values taken from the ESIMO ice maps made it possible to choose a combination of the model parameters that provides the best correspondence between the calculated and actual values.

Conclusions. It is shown that in reproducing the seasonal changes in the ice cover thickness in the Taganrog Bay top part in winter, 2016/17, the choice of the transmittance and extinction coefficients for white ice represented by the cloudiness functions, on the one hand, and the thickness of the layer with the most intense absorption of short-wave radiation $\sim 4 \mathrm{~cm}$, on the other, turned out to be the most justified.

Keywords: sea ice, thermodynamics, ice thickness, vertical ice temperature profile, short-wave radiation, extinction coefficient, Sea of Azov

Acknowledgments: the work was carried out within the framework of the state task on theme No. 0555-2021-0004 "Fundamental research of oceanological processes that determine state and evolution of marine environment under the influence of natural and anthropogenic factors, based on observation and modeling methods".

For citation: Zavyalov, D.D. and Solomakha, T.A., 2021. Parameterization of Solar Radiation Absorption by Snow-ice Cover in the Thermodynamic Sea Ice Model of the Sea of Azov. Physical Oceanography, [e-journal] 28(5), pp. 499-513. doi:10.22449/1573-160X-2021-5-499-513

DOI: $10.22449 / 1573-160 X-2021-5-499-513$

(C) D. D. Zavyalov, T. A. Solomakha, 2021

(C) Physical Oceanography, 2021

\section{Introduction}

Ice cover is an important part of the hydrological regime of the freezing seas. Sea ice is a complex heterogeneous formation in terms of thermophysical and ISSN 1573-160X PHYSICAL OCEANOGRAPHY VOL. 28 ISS. 5 (2021) 
optical properties. One of the main factors that form the thermal dynamics of the snow-ice cover and the temperature field in its thickness is solar radiation. Penetrating effect of solar radiation determines the spatio-temporal variation in thermophysical and radiation properties of sea ice and snow. Ice absorbed shortwave radiation accelerates the ice heating and decreases both temperature gradient, and, consequently, the heat flux into the ice from its surface. Snow on the sea ice surface significantly reduces the intensity of solar radiation penetrating into the snow-ice thickness. Therefore, parametrization of the solar radiation penetration process into the snow-ice cover of the freezing seas is important both in climatic models of the interaction of the atmosphere with the underlying surface and in regional thermodynamic models of sea ice.

The models of sea snow-ice cover thermodynamics are based on the solution of the heat conduction equations with a radiation source for snow and ice with the corresponding boundary conditions. In some cases [1-5], an approximate solution of the heat conduction equation was used without taking into account the volumetric absorption of radiation in the snow-ice layers. This simplification leads to the fact that the temperature profile in the snow-ice layers has the form of a linear function of the thickness of these layers.

In quite a large number of works [6-8], the heat conduction equation is solved in full nonstationary form. Interaction of thermal radiation with the sea ice-snow cover in these models is taken into account in the heat balance equation on its upper surface and in the description of radiation transfer in layers according to the Bouguer-Lambert law. However, this parameterization does not consider the essential role of the outer transition layer separating the atmosphere and the snow-ice bulk. It is in the near-surface transitional layer under the action of radiation that intense processes occur affecting the thermal regime of the main column [9].

In $[10,11]$, a two-layer scheme that simulates an energetically active nearsurface layer of ice, characterized by strong attenuation of short-wave radiation, is presented. Snow accumulating on the surface of the ice layer has a significant impact on almost all physical processes occurring in the ice. A detailed review of modern snow cover models is given in [12]. In [9, 13-15], algorithms for the solar radiation transfer in the snow mass, used in various models of interaction between the atmosphere and the underlying surface, are given.

A significant number of works are devoted to modeling the sea ice thermodynamics in polar regions where permanent ice cover is present $[1-3,7,8$, 10,11]. A characteristic feature of the Sea of Azov in winter is the great variability of the ice regime. Consequently, the formation of an extremely unstable snow-ice cover of the Sea of Azov will differ from the thermal evolution of sea ice at high latitudes. Ice regime features of the Sea of Azov and the reproduction of the main characteristics of the ice season based on observation data and the results of numerical modeling are presented in [16-18].

The present paper deals with the influence of various algorithms for accounting for radiation factors on the seasonal evolution of the snow-ice cover of the Sea of Azov within the framework of a non-stationary thermodynamic model of sea ice. Numerical experiments were carried out to reproduce the thermal dynamics of ice thickness at the Taganrog Bay top part $\left(4^{\circ} 11^{\prime} 39^{\prime \prime} \mathrm{N}, 38^{\circ} 54^{\prime} 59^{\prime \prime} \mathrm{E}\right)$ in 
the winter of 2016/17 using various schemes for parameterizing the radiation properties of snow-ice cover. The results of the model calculations of the ice thickness were compared with each other and with the actual sea ice thickness values from the ESIMO ${ }^{1}$ ice maps. It is shown how the differences in the parameterization schemes for the radiation properties of the snow-ice cover affect the simulation results.

\section{Thermodynamic model}

Reproduction of the seasonal cycle of ice crystallization/melting and snow accumulation/melting at its upper boundary is described by a nonstationary onedimensional thermodynamic model $[1-8,10,11]$. Heat distribution in snow-ice layers is determined by the heat conduction equations

$$
(\rho c)_{\mathrm{i}, \mathrm{s}} \frac{\partial T_{\mathrm{i}, \mathrm{s}}(\mathrm{z}, t)}{\partial t}=\frac{\partial}{\partial z}\left(k_{\mathrm{i}, \mathrm{s}} \frac{\partial T_{\mathrm{i}, \mathrm{s}}(\mathrm{z}, t)}{\partial \mathrm{z}}\right)-\frac{\partial \mathrm{I}_{\mathrm{i}, \mathrm{s}}(\mathrm{z}, t)}{\partial \mathrm{z}} .
$$

Boundary conditions for the equations (1) at the upper $(z=0)$ and lower $\left(z=h_{\mathrm{i}}(t)\right)$ surfaces of the snow-ice cover express the conditions of thermodynamic equilibrium:

$$
\begin{gathered}
-k_{\mathrm{i}, \mathrm{s}} \frac{\partial T_{\mathrm{i}, \mathrm{s}}}{\partial z}=F_{\mathrm{t}}\left(T_{\mathrm{sfc}}\right), \quad z=0, \\
-k_{\mathrm{i}} \frac{\partial T_{\mathrm{i}}}{\partial \mathrm{z}}=F_{\mathrm{b}}\left(T_{\mathrm{f}}, T_{\mathrm{w}}\right), \quad T_{\mathrm{i}}=T_{\mathrm{f}}, \quad z=h_{\mathrm{i}}(t) .
\end{gathered}
$$

On the snow-ice interface, the conditions of the heat flux and temperature continuity are satisfied:

$$
k_{\mathrm{s}} \frac{\partial T_{\mathrm{s}}}{\partial \mathrm{z}}=k_{\mathrm{i}} \frac{\partial T_{\mathrm{i}}}{\partial \mathrm{z}}, \quad T_{\mathrm{s}}=T_{\mathrm{i}}, \quad z=h_{\mathrm{s}}(t) .
$$

At the moving interfaces of various phases of a substance, the law of energy conservation during phase transitions is fulfilled:

$$
\begin{aligned}
& -\rho_{\mathrm{i}, \mathrm{s}} L_{\mathrm{fi}, \mathrm{s}} \frac{\partial h_{\mathrm{i}, \mathrm{s}}}{\partial t}=F_{\mathrm{t}}\left(T_{\mathrm{mi}, \mathrm{s}}\right)+k_{\mathrm{i}, \mathrm{s}} \frac{\partial T_{\mathrm{i}, \mathrm{s}}}{\partial \mathrm{z}}, \quad z=0, \\
& -\rho_{\mathrm{i}} L_{\mathrm{fi}} \frac{\partial h_{\mathrm{i}}}{\partial t}=F_{\mathrm{b}}\left(T_{\mathrm{f}}, T_{\mathrm{w}}\right)+k_{\mathrm{i}} \frac{\partial T_{\mathrm{i}}}{\partial \mathrm{z}}, \quad z=h_{\mathrm{i}}(t) .
\end{aligned}
$$

If the snow-ice cover is absent, then the mixed quasihomogeneous water layer is heated or cooled:

$$
\frac{\partial T_{\mathrm{w}}}{\partial t} \rho_{\mathrm{w}} c_{\mathrm{w}} h_{\mathrm{w}}=F_{\mathrm{b}}-F_{\mathrm{t}}-v \rho_{\mathrm{s}} L_{\mathrm{fs}}, \quad z \in\left[0, h_{\mathrm{w}}\right] .
$$

${ }^{1}$ Hydrometcentre. ESIMO. 2021. [online] Available at: http://193.7.160.230/web/esimo/azov/ice/ [Accessed: 13 September 2021] (in Russian). 
The initial water temperature and salinity are considered to be set:

$$
T_{\mathrm{w}}(\mathrm{z}, 0)=T_{\mathrm{w} 0}, S_{\mathrm{w}}(z, 0)=S_{\mathrm{w} 0}, z \in\left[0, h_{\mathrm{w}}\right] .
$$

Here $t$ is the time; $z$ is the vertical coordinate, the axis is directed downward from the upper surface of the snow-ice cover $(z=0)$; $\rho$ is the density; $h$ is the thickness; $T$ is the temperature; $S$ is the salinity; $c$ is the heat capacity; $k$ is the thermal conductivity; $L_{f}$ is the heat of fusion; $I_{\mathrm{i}, \mathrm{s}}$ is the short-wave solar radiation penetrating into the snow-ice thickness; $T_{\mathrm{sfc}}, T_{\mathrm{mi}, \mathrm{s}}$ and $T_{\mathrm{f}}$ are the temperature on the upper surface of the snow-ice cover, the melting point of ice/snow and the freezing point of water, respectively; $v$ is the rate of solid precipitation; $F_{t}$ is the heat flux from the atmosphere through the upper boundary of the snow-ice cover, consisting of turbulent fluxes of sensible and latent heat, long-wave and short-wave radiation balances, as well as heat fluxes associated with cooling processes and possible subsequent crystallization of liquid precipitation; $F_{\mathrm{b}}$ is the heat flux from the water to the lower ice boundary. Formulas for calculating heat fluxes, as well as parameterization of the processes of snow accumulation and melting on the upper surface of sea ice are given in $[4,19]$. Hereinafter, the indices $i, s, w$ and $a$ denote ice, snow, water and atmosphere, respectively.

\section{Snow-ice cover temperature calculation procedure}

Vertical structure of snow-ice system was represented by $N_{\mathrm{s}}$ amount of the snow layers having thickness $\Delta h_{\mathrm{s}}=h_{\mathrm{s}} / N_{\mathrm{s}}$ and $N_{\mathrm{i}}$ amount of the ice layers having thickness $\Delta h_{\mathrm{i}}=h_{\mathrm{i}} / N_{\mathrm{i}}$. Spatial coordinates of the internal nodes of the Lagrange grid were defined as $z_{j}=j \Delta h_{\mathrm{i}, \mathrm{s}}, j=1,2, \ldots, N_{\mathrm{i}, \mathrm{s}}-1$. The change in the time coordinate of the nodes has the form $t_{m}=m \tau, m=1,2,3, \ldots$, where $\tau$ is the integration step of the heat conduction equation with respect to time. Using the integral interpolation method, the equation (1) can be reduced to a finite-difference form [10]:

$$
\begin{aligned}
& -0.5 q A_{j-1}^{m+1} T_{j-1}^{m+1}+0.5\left[\rho c_{j}^{m+1}+\rho c_{j}^{m}+q A_{j}^{m+1}\right] T_{j}^{m+1}-0.5 q A_{j+1}^{m+1} T_{j+1}^{m+1}= \\
& 0.5 q A_{j-1}^{m} T_{j-1}^{m}+0.5\left[\rho c_{j}^{m+1}+\rho c_{j}^{m}-q A_{j}^{m}\right] T_{j}^{m}+0.5 q A_{j+1}^{m} T_{j+1}^{m}+Q_{j}^{m+1 / 2} \Delta t
\end{aligned}
$$

Here $\quad q=\frac{\Delta t}{\Delta h^{2}} ; A_{j-1}^{m}=0.5\left(k_{j-1}+k_{j}\right) ; \quad A_{j+1}^{m}=0.5\left(k_{j}+k_{j+1}\right) ; \quad A_{j}^{m}=A_{j-1}^{m}+A_{j+1}^{m}$; $Q_{j}^{m+1 / 2}$ depends on the form of presentation of the flux of penetrating short-wave solar radiation $I_{\mathrm{i}, s .}$. The heat capacity and thermal conductivity of sea ice were determined as

$$
c_{\mathrm{i}}\left(T_{\mathrm{i}}, S_{\mathrm{i}}\right)=c_{0}+\frac{L_{0} \mu S_{\mathrm{i}}}{T_{\mathrm{i}}^{2}},
$$




$$
k_{\mathrm{i}}\left(T_{\mathrm{i}}, S_{\mathrm{i}}\right)=k_{0}\left(T_{\mathrm{i}}\right)+\frac{\beta S_{\mathrm{i}}}{T_{\mathrm{i}}}, k_{0}\left(T_{\mathrm{i}}\right)=9.828 e^{-0.0057 T_{\mathrm{i}}},
$$

Where $c_{0}=2106 \mathrm{~J} /(\mathrm{kg} \cdot \mathrm{deg})$ is the heat capacity of fresh ice at $0^{\circ} \mathrm{C}$; $L_{0}=3.34 \cdot 10^{5} \mathrm{~J} / \mathrm{kg}$ is the latent heat of fusion of fresh ice at $0^{\circ} \mathrm{C} ; \mu=0.0544$ $\operatorname{deg} / \%, \quad \beta=0.117 \mathrm{~W} /(\mathrm{m} \% \%)$ are the empirical constants; $k_{0}\left(T_{\mathrm{i}}\right)$ is the thermal conductivity of fresh ice. Difference approximations (2)-(3) were written in the form [6]

$$
c^{m}{ }_{i j}=c_{0}+\frac{L_{0} \mu S_{i}^{m}}{T_{i j}^{m} T_{i j}^{m+1}}
$$

and

$$
k_{\mathrm{i} j}=k_{0 j}+\frac{\beta S_{\mathrm{i}}^{m}}{T_{\mathrm{i} 1}^{m}} ; j=1 ; k_{\mathrm{i} j}=k_{0 j}+\frac{2 \beta S_{\mathrm{i}}^{m}}{T_{\mathrm{i} j}^{m}-1+T_{\mathrm{i} j}^{m}} ; j=2, \ldots, N_{\mathrm{i}} ; k_{\mathrm{i} j}=k_{0 j}+\frac{\beta S_{\mathrm{i}}^{m}}{T_{\mathrm{f}}^{m}} ; j=N_{\mathrm{i}}+1
$$

respectively. The vertical mean ice salinity was calculated as $S_{\mathrm{i}}=S_{\mathrm{w}}\left(0.87 e^{-5 \sqrt{h_{i}}}+0.13\right)$ [20], and its density was calculated using the Weinberg formula

$$
\rho_{\mathrm{i}}\left(T_{l}\right)=917 \cdot\left(1-1.58 \cdot 10^{-4} T_{l}\right)(1-n),
$$

$n=5.25 \cdot 10^{-4} T_{\mathrm{a}}-2.35 \cdot 10^{-2}, T_{l}$ is the mean ice temperature. The increase in water salinity $\Delta S_{\mathrm{w}}$ as a result of ice formation was determined using $\Delta S_{\mathrm{w}}=$ $S_{\mathrm{i}} \Delta h /\left(h_{\mathrm{w}}+\Delta h\right)$ [1, p. 85], where $\Delta h$ is the increase in ice thickness over a time interval equal to the model step. If there is a snow cover on the ice surface, then the heat capacity of the snow was represented by a linear function of temperature [21], $c_{\mathrm{s}}=92.88+7.364 T_{\mathrm{s}}$, the thermal conductivity of snow was calculated by the formula $k_{\mathrm{s}}=9.165 \cdot 10^{-2}-3.814 \cdot 10^{-4} \rho_{\mathrm{s}}+2.905 \cdot 10^{-6} \rho_{\mathrm{s}}{ }^{2} \quad$ [22], and the thermal conductivity coefficient $k_{\text {int }}$ at the ice - snow interface, according to the condition of the continuity of the heat flux, $-k_{\mathrm{int}}=\frac{k_{\mathrm{i}} k_{\mathrm{s}}\left(\Delta h_{\mathrm{i}}+\Delta h_{\mathrm{s}}\right)}{\Delta h_{\mathrm{s}} k_{\mathrm{i} 1}+\Delta h_{\mathrm{i}} k_{\mathrm{s}}}$.

Since the thickness of the snow-ice layers does not remain constant, the coordinates of the grid nodes also change over time. In addition, the coordinate system moves in a vertical direction along with the snow-ice cover surface. A calculation procedure that takes into account the motion of boundaries when determining the temperature profile is described in [10]. The temperature at each node at the time step $m$ was considered known. After determining the thickness of the snow and ice at step $m$, the new position of each grid node at step $m+1$ was calculated, and the temperature values from the grid nodes at step $m$ were interpolated to these nodes. Then, the temperature at each node was calculated at step $m+1$ from the atmospheric forcing data. The heat conduction equation solution was repeated with a new initial approximation $T^{m+1}$ obtained at PHYSICAL OCEANOGRAPHY VOL. 28 ISS. 5 (2021) 
the previous iteration. The iterative procedure continued until the solution converged, when the temperature at each node stopped changing at step $m+1$.

\section{Numerical simulation results}

Based on the constructed thermodynamic model, numerical experiments were carried out to assess the influence of the method of parametrizing the solar heat absorption process by the snow-ice cover on the simulation of the ice temperature profiles and the seasonal evolution of its thickness at the Taganrog Bay top

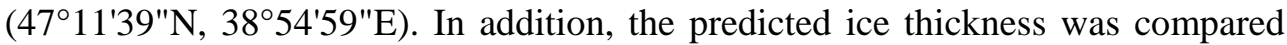
with the actual values from the ESIMO ice maps. The ESIMO maps initial data and the description of ice conditions are both sea ice cover images obtained from artificial Earth satellites and data from coastal hydrometeorological stations and posts. As an external forcing (surface temperature, atmospheric pressure, humidity, total cloudiness, wind speed and total precipitation), data from eight-term observations of the main meteorological parameters of RIHMI-WDC ${ }^{2}$ at the Taganrog meteorological station was used. At the calculation period start, the monthly mean climatic values of water temperature and salinity were set. The cooled surface (water, snow/ice) and under-ice seawater temperature, were subsequently calculated using the heat balance equations. The spatial model (vertical) resolution was determined by $5\left(N_{s}=5\right)$ nodes for the snow layer and $18\left(N_{i}=18\right)$ nodes for the ice layer. The time integration step $\tau$ was 30 min $(1 / 6$ of the atmospheric forcing step).

Consider the interaction of short-wave radiation with a snow cover located on the surface of sea ice at first. As is known, the incident solar radiation not only participates in the heat balance formation of the thin upper snow layer, but also transfers heat deep into the snow mass, penetrating into it to a considerable depth [13]. The process of radiation intensity attenuation with depth can be described by the Bouguer-Lambert law $I_{\mathrm{s}}=i_{0}\left(1-\alpha_{\mathrm{s}}\right) Q_{s}(t) e^{-\kappa_{\mathrm{s}} z}$ where $Q_{\mathrm{s}}$ is the short-wave solar radiation coming to the snow surface; $\alpha_{\mathrm{s}}$ is albedo, $\kappa_{\mathrm{s}}$ is the extinction coefficient, $\mathrm{m}^{-1}$.

Due to the significant dependence both on the snow layer structure the spectral composition of the incident radiation, the variation range in $\kappa_{\mathrm{s}}$ values is quite wide: from $5 \mathrm{~m}^{-1}$ for wet coarse snow to $50 \mathrm{~m}^{-1}$ and more for loose fresh snow [13, 23]. Since a strict determination of the extinction coefficient in each specific case is very difficult, when constructing numerical models, as a rule, certain assumptions simplifying the selection of the extinction coefficient value are made. In particular, it was assumed that long-wave radiation is absorbed by a thin upper layer of snow, and the extinction coefficient of the short-wave part of the spectrum was either assumed to be equal to a constant independent of the thermophysical characteristics of snow [10, 15], or was presented as a snow density function, for example $[14,24]$.

${ }^{2}$ Hydrometcentre. RIHMI-WDC. 2021. [online] Available at: http://meteo.ru [Accessed: 13 September 2021]. 

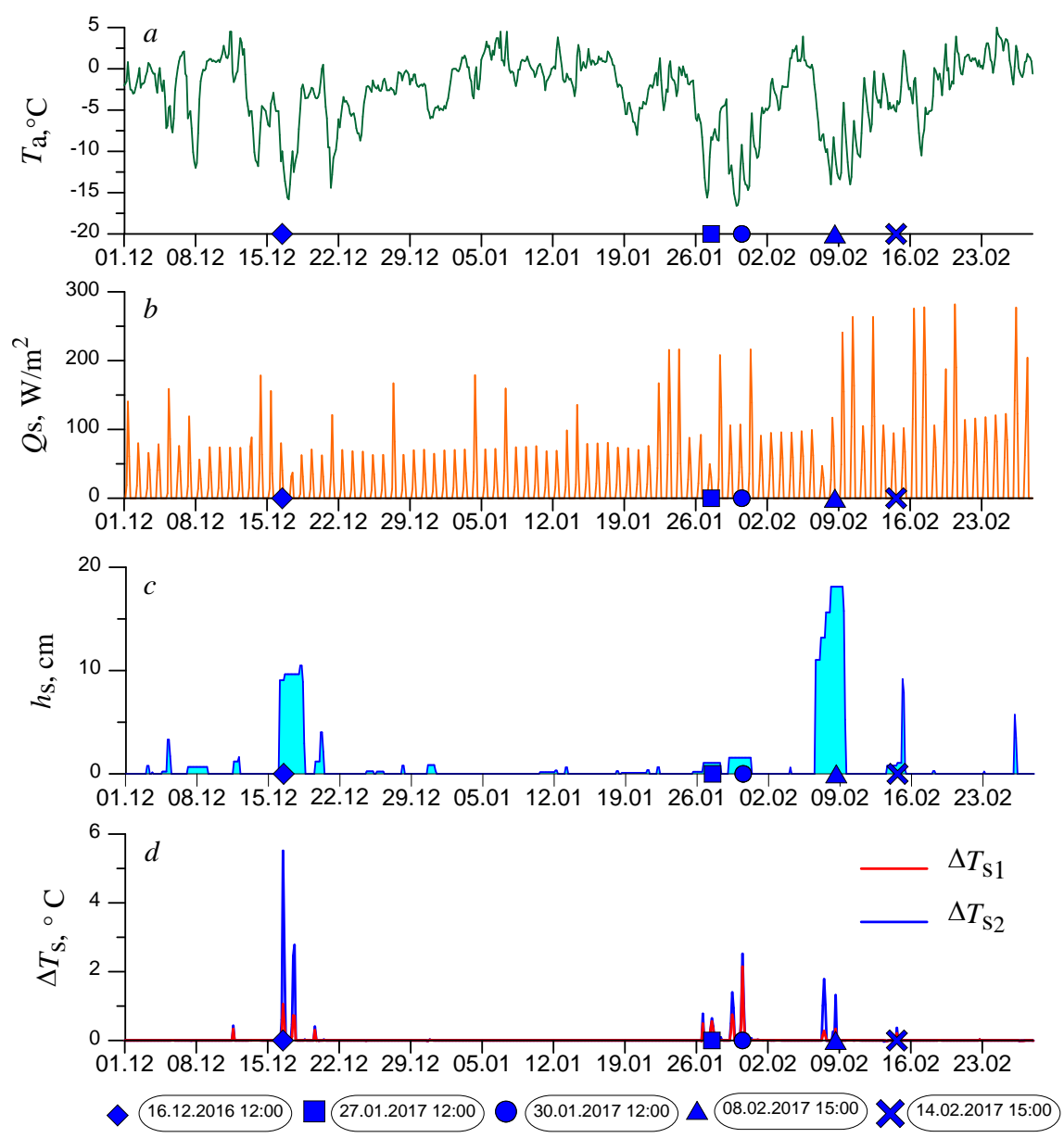

F i g. 1. Air temperature at the height $2 \mathrm{~m} T_{\mathrm{a}},{ }^{\circ} \mathrm{C}(a)$, short-wave solar radiation $Q_{\mathrm{s}}, \mathrm{W} / \mathrm{m}^{2}$ falling on the surface of the snow-ice cover $(b)$, snow height $h_{\mathrm{s}}$, $\mathrm{cm}(c)$, and temperature difference at the boundaries of the first (top) snow layer calculated for $\kappa_{\mathrm{S}}$ equal to 5 and $50 \mathrm{~m}^{-1}(d)$

To assess the model sensitivity to the quantity choice, four options for its determination are considered: 1) $\kappa_{\mathrm{s}}^{1}=5 \mathrm{~m}^{-1}$; 2) $\kappa_{\mathrm{s}}^{2}=0.1311 \rho_{\mathrm{s}}+3.445 \mathrm{~m}^{-1}$ [27]; 3) $\left.\kappa_{\mathrm{s}}^{3}=\min \left(65 ; 0.06 \rho_{\mathrm{s}}+32\right) \mathrm{m}^{-1}[26] ; 4\right) \kappa_{\mathrm{s}}^{4}=50 \mathrm{~m}^{-1}$. Fig. 1 shows air temperature at the height $2 \mathrm{~m} T_{\mathrm{a}},{ }^{\circ} \mathrm{C}$ (Fig. 1, a), short-wave solar radiation $Q_{\mathrm{s}}, \mathrm{W} / \mathrm{m}^{2}$ falling on the surface of the snow-ice cover (Fig. 2,b), snow height $h_{\mathrm{s}}$, cm (Fig. 2, c), and temperature difference at the boundaries of the first (top) snow layer calculated for $\kappa_{\mathrm{S}}$ equal to 5 and $50 \mathrm{~m}^{-1}$ (Fig. 2, d).

Here $\Delta T_{\mathrm{s} 1}\left(\Delta T_{\mathrm{s} 1}=T_{\mathrm{s} 1}\left(\kappa_{\mathrm{s}}^{4}\right)-T_{\mathrm{s} 1}\left(\kappa_{\mathrm{s}}^{1}\right)\right)$ is the temperature difference at its upper $\left(T_{\mathrm{s} 1}\right)$, a $\Delta T_{\mathrm{s} 2}\left(\Delta T_{\mathrm{s} 2}=T_{\mathrm{s} 2}\left(\kappa_{\mathrm{s}}^{4}\right)-T_{\mathrm{s} 2}\left(\kappa_{\mathrm{s}}^{1}\right)\right)-$ lower boundaries $\left(T_{\mathrm{s} 2}\right)$.

\footnotetext{
${ }^{3}$ Machulskaya, E.E., 2001. [Modeling and Diagnosis of Heat and Moisture Exchange Processes between the Atmosphere and Land in a Cold Climate].PhD Thesis. Moscow, 22 p. (in Russian).
} 
In Fig. 2 for dates marked with symbols on the time axes of the graphs in Fig. 1 the temperature profiles of snow obtained for all four variants of determination are shown. The dates were selected from the condition of a noticeable difference in temperatures in the upper layer of snow, obtained in calculations using the described definition options (Fig. 1, d). Size of the spatial step of the computational grid for cases in Fig. 2 correspond to the distance between the dotted lines, plotted along the vertical z-axis.

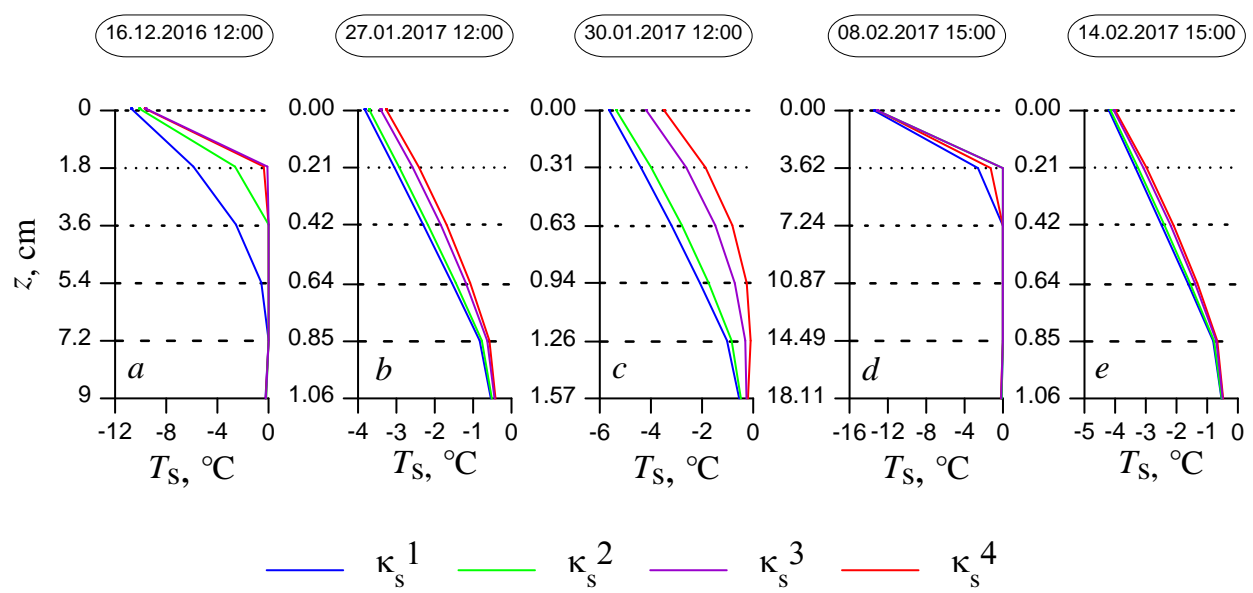

F i g. 2. Vertical temperature profiles of snow for different variants for determining the extinction coefficient $\kappa_{\mathrm{S}}$

Unfortunately, there is no information on in situ temperature measurements in the snow-ice column for this region, therefore, the calculated profiles for different determination options were compared only with each other. Fig. 1, 2 show that during the entire ice season, the differences in daytime temperatures on the snow surface, determined from the calculated profiles, did not exceed $2{ }^{\circ} \mathrm{C}$ even in the case of choosing the extreme values of $\kappa_{\mathrm{s}}\left(\kappa_{\mathrm{s}}^{1}, \kappa_{\mathrm{s}}^{4}\right)$. At the lower boundary of the first snow layer, the temperature difference was slightly higher than at the surface and reached $2-5^{\circ} \mathrm{C}$. This difference became less noticeable in the lower layers and was $0.1-0.2^{\circ} \mathrm{C}$ at the snow-ice boundary. For the profiles corresponding to $\kappa_{\mathrm{s}}^{2}$ and $\kappa_{\mathrm{s}}^{3}$, which, as a rule, occupy an intermediate position between the profiles calculated by $\kappa_{\mathrm{s}}^{4}$ and $\kappa_{\mathrm{s}}^{1}$, these differences in temperature are even smaller.

For four variants of the $\kappa_{\mathrm{s}}$ determination, the differences in the $T_{\mathrm{s}}(\mathrm{z})$ distributions had almost no effect on the model snow cover thickness (Fig. 1, c), since they fell on periods with a sufficiently low air temperature (Fig. 1, $a, 1, d$ ). The choice of different variants of determination also did not affect the thermal evolution of the ice thickness, since the differences in temperature at the snow-ice boundary were very small and short-term. For a relatively thin and unstable snow cover throughout the entire ice season, rapid melting is characteristic for all variants of determining the extinction coefficient. 
Below the role of the transmission $i_{0}$ and extinction $\kappa_{\mathrm{i}}$ coefficients in the parametrization of the short-wave radiation penetration into the ice depth is estimated. As in the case of the snow cover, it was assumed that the radiation decay in the ice occurs according to an exponential law $I_{\mathrm{i}}=i_{0}\left(1-\alpha_{\mathrm{i}}\right) Q_{s}(t) e^{-\mathrm{k}_{\mathrm{i}} Z}$, where $Q_{\mathrm{s}}$ is the short-wave solar radiation coming at the ice surface; $\alpha_{\mathrm{i}}$ is albedo. In the course of numerical experiments, variants of complete $\left(i_{0}=0\right)$ and partial $\left(i_{0}=0.3\right)$ short-wave energy absorption directly by the ice surface and a two-layer scheme of solar radiation penetration into ice were considered [10]. In this scheme, it is assumed that a certain surface layer of ice with a thickness $z_{0}$ is distinguished, in which the radiation attenuation occurs most intensely. It is believed that for $0<z \leq z_{0}$ the attenuation of the solar energy intensity can be described as $I_{\mathrm{i}}=\left(1-\alpha_{\mathrm{i}}\right) Q_{s}(t) e^{-\kappa_{\mathrm{i} 1} z}$, and for $z_{0}<z \leq h_{\mathrm{i}}-I_{\mathrm{i}}=i_{0}\left(1-\alpha_{\mathrm{i}}\right) Q_{s}(t) e^{-\kappa_{\mathrm{i} 2}\left(z-z_{0}\right)}$. The extinction coefficient value at the ice surface can differ by an order of magnitude from its value in the ice mass. In the calculations, the expressions for $i_{0}$, $\kappa_{\mathrm{i}}$, given for white (thin first-year) ice [23, 25]: $i_{0}=0.18(1-C)+0.35 C$; $\kappa_{\mathrm{i} 1}=17.1(1-C)+10.5 C \mathrm{~m}^{-1}, \kappa_{\mathrm{i} 2}=1.5 \mathrm{~m}^{-1} ; C$ - cloud factor $(0$ to 1$)$.

The results of calculations of the seasonal variation of the ice thickness obtained during numerical experiments with various options for the parameterization of the solar radiation absorption process were compared with each other and with the actual values of the ice thickness according to the ESIMO data. The model's forecast quality was assessed according to the following quantitative characteristics (here $h_{\mathrm{obs}}$ and $h_{\mathrm{i}}$ are the actual and calculated ice thickness; $l=16$ is the time series length):

a) mean forecast error $\mathrm{ME}=\sum_{l} \frac{h_{\mathrm{obs}}-h_{i}}{l} ;$
b) mean absolute forecast error $\mathrm{MAE}=\sum_{l} \frac{\left|h_{\mathrm{obs}}-h_{i}\right|}{l}$;

c) rms deviation $\sigma=\sqrt{\sum_{l} \frac{\left(h_{\mathrm{obs}}-h_{i}\right)^{2}}{l}}$;

d) sample determination coefficient $R^{2}=1-\frac{\sum_{l}\left(h_{\mathrm{obs}}-h_{i}\right)^{2}}{\sum_{l}\left(h_{\mathrm{obs}}-\bar{h}_{\mathrm{obs}}\right)^{2}}$;

e) Theil index $v=\sqrt{\frac{\sum_{l}\left(h_{\mathrm{obs}}-h_{i}\right)^{2}}{\sum_{l}\left(h_{\mathrm{obs}}\right)^{2}+\sum_{l}\left(h_{i}\right)^{2}}} ;$

f) forecast predictability $P=\frac{1}{l} \sum_{i=1}^{l} p_{i} \cdot 100 \%$. 
If the ice thickness forecast did not go beyond a certain permissible error $\varepsilon$, it was considered justified and the predictability value $p_{i}$ was equated to 1 , otherwise - to 0 . The permissible error in assessing the ice thickness forecast was 20 and $30 \%$ of the actual value ${ }^{4}$. The values of these characteristics for five variants of the parameterization of solar radiation absorption by sea ice are presented in the table below. Fig. 3 shows the curves of the seasonal variation of the ice thickness corresponding to these variants of calculations. The gray circles represent actual sea ice thickness data.

As can be seen, the calculated ice thickness in the case of the assumption of complete absorption of short-wave energy by the ice surface (variant 1 ) turned out to be significantly underestimated throughout almost the entire ice period. In particular, the calculated maximum ice thickness turned out to be $\sim 3 \mathrm{~cm}$ less than the actual one, and the forecast quality assessment turned out to be the most unsuccessful of the variants considered.

Somewhat better results were obtained by calculations of $h_{\mathrm{i}}$ according to variant 2 , when $70 \%$ of the short-wave energy is absorbed directly by the surface. This assumption is very widespread [2,7], and with the value of the permissible error $\varepsilon=30 \%$, the ice thickness forecast $\left(\mathrm{P}_{30}>70 \%\right)$ can be considered satisfactory. However, it turned out that when the assessment criterion is toughened to $\varepsilon=20 \%$, the forecast quality deteriorates greatly.

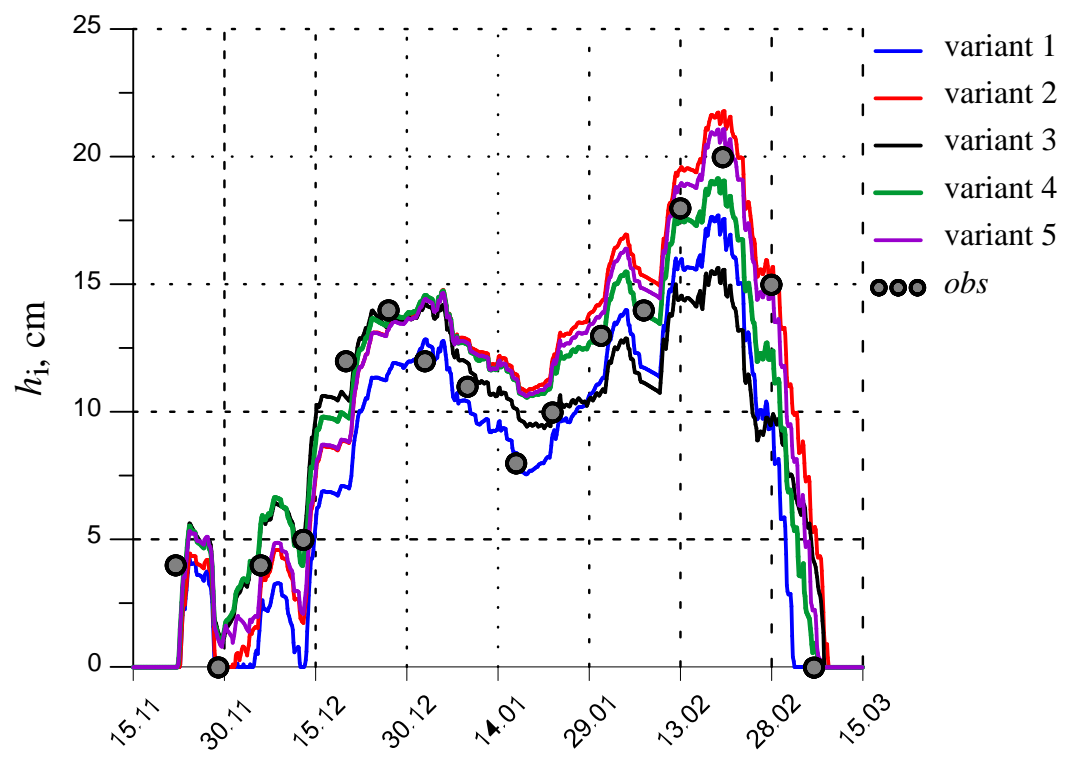

F i g. 3. Seasonal variation of ice thickness for the variants represented in the table

Next, the results of calculations using a two-layer scheme of penetration of solar radiation into ice (variant 3-5) are considered. The quantitative characteristics of the forecast quality for variant 3 , obtained when setting the thickness of the upper

${ }^{4}$ Hydrometcentre, 2011.Manual on Forecasting Service. Guidance document 52.27.7592011.Moscow: TRIADA LTD. Section 3, Part III: Marine Hydrological Forecast Service, 189 p. (in Russian). 
absorption layer $z_{0}=10 \mathrm{~cm}$ [10], turned out to be worse than those obtained for variant 2 . However, it should be borne in mind that during the period of maximum development of the ice cover on the considered parts of the Sea of Azov the shapes of gray or gray-white ice ${ }^{5}$ dominated, and the values of the empirical coefficients $i_{0}, \kappa_{i 1}$ and $\kappa_{i 2}$ and the thickness $z_{0}$ used in the model, were obtained for white ice.

To determine the possibility of forecast improvement by choosing the optimal value of the upper absorption layer thickness, calculations with $z_{0}$ varying from 10 to $1 \mathrm{~cm}$ with a step of $1 \mathrm{~cm}$ were carried out. Numerical experiments showed that the best results of modeling the seasonal ice thickness evolution are obtained at $z_{0}=$ $=4 \mathrm{~cm}$ (variant 4). It should be noted that for variant 4 , a satisfactory forecast $h_{\mathrm{i}}$ is realized with an admissible error of both 30 and $20 \%$.

Unfortunately, due to the lack of field data on the temperature distribution in ice, the comparison of the calculated $T_{\mathrm{i}}(z)$ dependences was possible. Fig. 4 shows the temperature profiles obtained for two days in February 2017, when the ice cover thickness almost reached its seasonal maximum and was $\sim 20 \mathrm{~cm}$, the meteorological conditions on these days were noticeably different from each other. On February 14, overcast clouds were observed, on the surface of the ice there was a small $(\sim 1 \mathrm{~cm})$ snow cover, and the air temperature during the day was close to $-4^{\circ} \mathrm{C}$. On February 16, on the contrary, it was a cloudless clear day, the surface of the ice cover was free of snow, and the air temperature dropped from -2 to $-11^{\circ} \mathrm{C}$ during the day.
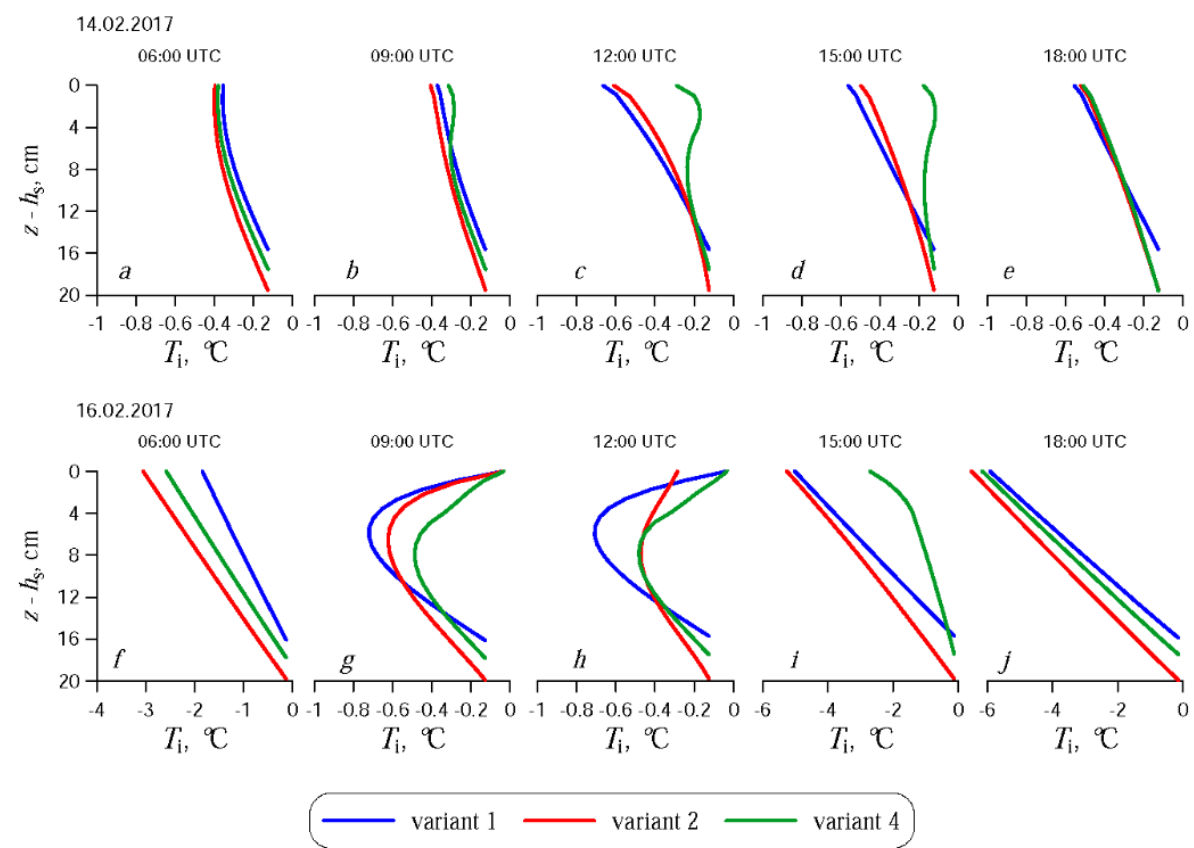

F i g. 4. Vertical temperature profiles of ice

\footnotetext{
${ }^{5}$ Hydrometcentre. ESIMO. 2021. [online] Available at: http://193.7.160.230/web/esimo/azov/ice/ [Accessed: 13 September 2021] (in Russian).
} 
For comparison, calculation options 1, 2, and 4 were selected (table). As can be seen from the figure, at night and in the morning the lowest forecasted temperature in ice is given by calculation according to variant 2 , and the highest according to variant 1 . Naturally, during the hours of darkness, the temperature difference determined from the presented curves is small and on average is 0.3$0.5^{\circ} \mathrm{C}$. In the daytime, especially in the absence of cloudiness and snow cover, this difference is more noticeable. In particular, on February 16 at 15:00, the differences in the values of the predicted temperature in the upper ice layer were $2.5-3^{\circ} \mathrm{C}$. It should be noted that daytime subsurface heating and a higher ice temperature are calculated according to variant 4 . Of course, for further verification of the model and refinements in the selection of its parameters, it is necessary to compare model calculations with the data of field measurements of the temperature snow-ice cover profile.

\section{Comparison of the results of calculations of the ice thickness seasonal variation using different schemes of absorption of short-wave solar radiation}

\begin{tabular}{|c|c|c|c|c|c|c|c|c|}
\hline $\begin{array}{l}\text { Variant } \\
\text { number }\end{array}$ & $\begin{array}{l}\text { Calculation } \\
\text { parameters }\end{array}$ & $\mathrm{ME}, \mathrm{cm}$ & MAE, cm & $\sigma, \mathrm{cm}$ & $R^{2}$ & $v$ & $P_{20}, \%$ & $P_{30}, \%$ \\
\hline \multicolumn{9}{|c|}{ One-layer scheme ( $i_{0}-$ const; $\kappa_{i}-$ const $)$} \\
\hline 1 & $i_{0}=0$ & 2.32 & 2.50 & 3.00 & 0.59 & 0.131 & 64.3 & 64.3 \\
\hline 2 & $\begin{array}{l}i_{0}=0.3 \\
\kappa_{\mathrm{i}}=1.5 \mathrm{~m}^{-1}\end{array}$ & -0.31 & 2.03 & 2.28 & 0.76 & 0.089 & 50 & 78.6 \\
\hline \multicolumn{9}{|c|}{ Two-layer scheme $\left(i_{0}=i_{0}(C) ; \kappa_{\mathrm{i}}=\kappa_{\mathrm{i}}(z, C)\right)$} \\
\hline 3 & $z_{0}=10 \mathrm{~cm}$ & 1.25 & 2.23 & 2.73 & 0.66 & 0.117 & 57.1 & 71.4 \\
\hline 4 & $z_{0}=4 \mathrm{~cm}$ & 0.07 & 1.60 & 1.98 & 0.83 & 0.080 & 71.4 & 78.6 \\
\hline 5 & $z_{0}=1 \mathrm{~cm}$ & -0.10 & 1.76 & 2.10 & 0.80 & 0.083 & 64.3 & 71.4 \\
\hline
\end{tabular}

\section{Conclusion}

Influence of the choice of the parameterization method for the solar heat absorption by the snow-ice cover on the simulation of the temperature profiles of ice and the seasonal evolution of its thickness at the Taganrog Bay top in winter 2016/17 is estimated. The choice of any of the considered options for determining the snow extinction coefficient had almost no effect on the simulation of the thermal evolution of the ice thickness. The choice of parameterization of 
the radiation properties of ice noticeably affects the simulation of seasonal changes in its thickness. Thus, the most successful from the viewpoint of comparing the ice thickness with actual data were the results of calculations using a two-layer scheme of solar radiation penetration into ice. In this case, the transmittance and extinction coefficients for white ice were presented as functions of cloudiness, and the layer thickness of the most intense absorption of short-wave radiation was taken to be $4 \mathrm{~cm}$. The calculated temperature profiles of ice also turned out to be sensitive to the values of the transmittance and extinction coefficients. Thus, in the daytime, in the absence of cloudiness and snow cover, the difference in the forecasted temperature in the upper ice layer was $2.5-3^{\circ} \mathrm{C}$. However, for further verification of the model and refinements in the selection of its parameters, it is necessary to compare the model calculations with the data of field measurements of the temperature snow-ice cover profile.

\section{REFERENCES}

1. Klyachkin, S.V., Guzenko, R.B. and May, R.I., 2015. Numerical Model of the Ice Cover Evolution in Arctic Seas for the Operational Forecasting. Ice and Snow, 55(3), pp. 83-96. doi:10.15356/2076-6734-2015-3-83-96 (in Russian).

2. Kulakov, M.Yu., Makshtas, A.P. and Shutilin, S.V., 2012. AARI-IOCM - Coupled IceOcean Circulation Model for the Arctic Ocean. Problemy Arktiki i Antarktiki, (2), pp. 6-18 (in Russian).

3. Yakovlev, N.G., 2009. Reproduction of the Large-Scale State of Water and Sea Ice in the Arctic Ocean in 1948-2002: Part I. Numerical Model. Izvestiya, Atmospheric and Oceanic Physics, 45(3),pp. 357-372.https://doi.org/10.1134/S0001433809030098

4. Zavyalov, D.D., 2020. Influence of the Atmospheric Precipitation Phase Composition on Seasonal Evolution of Snow-Ice Cover in the Taganrog Bay Apex. Physical Oceanography, 27(2), pp. 387-396. doi:10.22449/1573-160X-2020-2-126-141

5. Zav'yalov, D.D. and Solomakha, T.A., 2019. Snow Cover Influence on Sea Ice in the Taganrog Bay. Russian Meteorology and Hydrology, 44(1), pp. 45-52. doi:10.3103/S1068373919010059

6. Hunke, E.C., Lipscomb, W.H., Turner, A.K., Jeffery, N. and Elliott, S., 2015. CICE: the Los Alamos Sea Ice Model. Documentation and Software User's Manual. Version 5.1 LA-CC-06012. Los Alamos National Laboratory, 116 p. Available at: http://oceans11.lanl.gov/trac/CICE/attachment/wiki/WikiStart/cicedoc.pdf [Accessed: 13 September 2021].

7. Andreev, O.M. and Ivanov, B.V., 2001. Parametrization of Radiation Processes in the Ice Cover Model. Meteorologiya i Gidrologiya, (2), pp. 81-88 (in Russian).

8. Andreev, O.M. and Ivanov, B.V., 2003. Parametrization of Short-Wave Radiation Transfer in Snow-Ice Cover. Meteorologiya i Gidrologiya, 2, pp. 54-58 (in Russian).

9. Krass, M.S. and Merzlikin, V.G., 1990. [The Radiative Thermophysics of Snow and Ice]. Leningrad: Hydrometeoizdat, 260 p. (in Russian).

10. Cheng, B. and Launiainen, J., 1998. A One-Dimensional Thermodynamic Air-Ice-Water Model: Technical and Algorithm Description Report. Finnish Institute of Marine Research, 1998.MERI - Report Series of the Finnish Institute of Marine Research. Helsinki, Finland: Finnish Institute of Marine Research. No. 37. pp. 15-35. Available at: https://helda.helsinki.fi/bitstream/handle/10138/157940/Meri\%20No\%2037\%201998\%20 OCR.pdf?sequence=1\&isAllowed=y [Accessed: 07 September 2021].

11. Cheng, B., 2002. On the Numerical Resolution in a Thermodynamic Sea-Ice Model. Journal of Glaciology, 48(161), pp. 301-311. doi.org/10.3189/172756502781831449 
12. Armstrong, R.L. and Brun, E., eds., 2008. Snow and Climate: Physical Processes, Surface Energy Exchange and Modelling. Cambridge, UK: Cambridge University Press, 256 p.

13. Kuzmin, P.P., 1957. [Physical Properties of the Snow Cover]. Leningrad: Hydrometeoizdat, 179 p. (in Russian).

14. Shmakin, A.B., Turkov, D.V. and Mikhailov, A.Yu., 2009. Model of Snow Cover with Inclusion of Layered Structure and Its Seasonal Evolution. Kriosfera Zemli, 13(4), pp. 69-79 (in Russian).

15. Lecomte, O., Fichefet, T., Vancoppenolle, M. and Nicolaus, M., 2011. A New Snow Thermodynamic Scheme for Large-Scale Sea-Ice Models. Annals of Glaciology, 52(57), pp. 337-346.https://doi.org/10.3189/172756411795931453

16. Dashkevich, L.V., Nemtseva, L.D. and Berdnikov, S.V., 2016. Assessment of the Sea of Azov Ice Cover in the XXI century Using Terra/AquaModis Images and Numerical Modelling. Sovremennye Problemy Distantsionnogo Zondirovaniya Zemli iz Kosmosa, 13(5), pp. 91-100. doi:10.21046/2070-7401-2016-13-5-91-100 (in Russian).

17. Chikin, A.L. and Chikina, L.G., 2020. Modelling of Ice Formation Process in the Taganrog Bay. Studies of the Southern Scientific Centre of the Russian Academy of Sciences, 8, pp. 6164. doi:10.23885/1993-6621-2020-8-61-64 (in Russian).

18. Matishov, G.G., Dashkevich, L.V. and Kirillova, E.E., 2020. Ice as an Indicator of Climate Change (on Example of the Barents Sea and the Sea of Azov). Science in the South of Russia, 16(2), pp. 27-40 (in Russian).

19. Zavyalov, D.D., 2019. Reconstruction of the Ice Thickness Seasonal Evolution in the Northeastern Sea of Azov Using Different Arrays of Meteorological Data. Physical Oceanography, 26(3) pp. 247-259. doi:10.22449/1573-160X-2019-3-247-259

20. Ryvlin, F.Ya.,1974. [Method for Predicting the Ultimate Strength of the Ice Cover for Bending]. Problemy Arktiki i Antarktiki, (45), pp. 79-86 (in Russian).

21. Ebert, E.E. and Curry, J.A., 1993. An Intermediate One-Dimensional Thermodynamic Sea Ice Model for Investigating Ice-Atmosphere Interactions. Journal of Geophysical Research: Oceans, 98(C6), pp. 10085-10109. https://doi.org/10.1029/93JC00656

22. Osokin, N.I., Sosnovskiy, A.V. and Chernov, R.A., 2017. Effective Thermal Conductivity of Snow and Its Variations. Kriosfera Zemli, 21(3), pp. 55-61 (in Russian).

23. Perovich, D.K., 1996. The Optical Properties of Sea Ice. Monograph 96-1. Hanover, USA: U.S. Army Cold Regions Research and Engineering Laboratory, 25 p. Available at: https://erdc-library.erdc.dren.mil/jspui/bitstream/11681/2648/1/CRREL-Mono-96-1.pdf [Accessed: 07 September 2021).

24. Jordan, R., 1991. A One-Dimensional Temperature Model for a Snow Cover. Technical Documentation for SNTHERM.89. CRREL Special Report 91-16. Hanover, USA: US Army Corps of Engineers, 62 p. Available at: https://erdclibrary.erdc.dren.mil/jspui/bitstream/11681/11677/1/SR-91-16.pdf [Accessed: 07 September 2021).

25. Grenfell, T.C. and Maykut, G.A., 1977. The Optical Properties of Ice and Snow in the Arctic Basin. Journal of Glaciology, 18(80), pp. 445-463. https://doi.org/10.3189/S0022143000021122

About the authors:

Dmitriy D. Zavyalov, Senior Research Associate, Marine Hydrophysical Institute of RAS (2 Kapitanskaya St., Sevastopol, 299011, Russian Federation), Ph. D.,Scopus Author ID: 6506347014, ORCID ID: 0000-0002-7444-980X,zavyalov.dd@mhi-ras.ru

Tatiana A. Solomakha, Junior Research Associate, Marine Hydrophysical Institute of RAS (2 Kapitanskaya St., Sevastopol, 299011, Russian Federation), solomaxa.ta@mhi-ras.ru 
Contribution of the co-authors:

Dmitriy D. Zavyalov - general scientific management of the research, formulation of research goals and objectives, development and implementation of numerical experiments, qualitative analysis of the results and their interpretation, discussion of the study results, formulation of conclusions.

Tatiana A. Solomakha - literature review on the research problem, qualitative analysis of the results and their interpretation, processing and description of research results, discussion of the study results, formulation of conclusions, preparation of the paper text, revision of the text.

All the authors have read and approved the final manuscript.

The authors declare that they have no conflict of interest. 